\title{
Multifocal epithelial hyperplasia: A potentially precancerous disease? (Review)
}

\author{
A. BASCONES-MARTÍNEZ, S. COK, C. BASCONES-ILUNDÁIN, S. ARIAS-HERRERA, \\ R. GOMEZ-FONT and J.BASCONES-ILUNDÁIN
}

Department of Medicine and Buccofacial Surgery, School of Dentistry, UCM, Madrid, Spain

Received July 6, 2011; Accepted October 11, 2011

DOI: $10.3892 / \mathrm{ol} .2011 .465$

\begin{abstract}
Multifocal epithelial hyperplasia (MEH), also known as Heck's disease, manifests as a papulonodular lesion in the oral mucosa and has been associated with the human papillomavirus, a virus related to various precancerous diseases in the oral cavity. It has a predisposition for the female gender and for children. Although the majority of reported cases have been among American Indians and Eskimos, it has been described in multiple ethnic groups in various geographical locations. The objective of this review was to report on the clinical characteristics and epidemiology of $\mathrm{MEH}$ and its possible correlation with oral cancer. It is based on a search of articles in international journals published prior to April 2011, using the PubMed database and selecting articles related to the epidemiology and clinical characteristics of MEH. The review revealed a higher number of cases in individuals of American Indian origin and a predilection of the disease for the female gender and for patients between the 1st and 2nd decades of life. The most frequent lesion site was the lower lip. The disease has been associated with socio-economic and genetic factors, among others. No cases of malignant transformation have been reported.
\end{abstract}

\section{Contents}

1. Introduction

2. Human papillomavirus and other etiological factors

3. Diagnosis, prognosis and treatment

4. Criteria and variables included

5. Findings pertaining to multifocal epithelial hyperplasia

6. Conclusions

Correspondence to: Dr Antonio Bascones-Martínez, Department of Stomatology, School of Dentistry, UCM, Plaza de Ramón y Cajal 3, Ciudad Universitaria, 28040 Madrid, Spain

E-mail: antabasco@odon.ucm.es

Key words: focal epithelial hyperplasia, multifocal epithelial hyperplasia, Heck's disease, papillomavirus infections, human papillomavirus 13 and 32

\section{Introduction}

Multifocal epithelial hyperplasia (MEH) is an uncommon disease characterized by the proliferation on the oral mucosa of multiple papulonodular lesions, which are smooth, soft on palpation and generally asymptomatic (1-5). It has mainly been observed among isolated groups of native Indians in North, Central and South America and in other very small population groups in Europe and Africa (6-13).

Although previously described by other authors, the first case report was published by Dr Heck and his team in 1965, and it is therefore also known as Heck's disease (14). In the same year, Witkop et al reported 11 cases with the same diagnosis among Xavante Indians in Brazil, a Ladino population in El Salvador and Quiche-Mayan Indians in Guatemala (13). Single cases were subsequently reported in Polynesia (15), Puerto Rico (16), in an adult female Caucasian (17), and in small population groups in Bolivia, Paraguay, Peru, Colombia and Mexico $(12,18-20)$. The disease has also been found in primates and in a rabbit, which presented with macroscopic and microscopic characteristics similar to those of humans with the disease (21-25).

\section{Human papillomavirus and other etiological factors}

The main etiological factor for this disease is the presence of the human papillomavirus (HPV), which belongs to a varied group of DNA viruses from the Papillomaviridae family. Similar to all viruses in this family, it only establishes productive infections in the stratified epithelium of skin and mucosa of humans and certain animals (26).

In 1971, Praetorious-Clausen and Willis first revealed HPV particles in MEH, using an electron microscope to study five samples from patients in Greenland (27). One year later, Hanks et al reported the same findings in a 5-year-old child from Cochabamba in Bolivia (28). This association was subsequently confirmed by other authors, including Kuffer and Perol in 1976, in the first reported case in France (29), and Kulhwein et al in 1981 (30).

Approximately 200 different types of HPV have been identified, mostly asymptomatic (26). In 1983, Pfiser et al related the disease to HPV-13 after examining a sample from a Turkish patient (31). Beaudenon et al confirmed this specific association in 10 patients of various origins and also observed a correlation 
with HPV-32 (32). Over the past few years, immunohistochemical and in situ hybridization studies have shown $\mathrm{MEH}$ to be closely related to HPV-13 and HPV-32, while certain studies have also demonstrated the presence of HPV-1, HPV-6, HPV-11 and HPV-16 in these patients (33-36).

Genetic predisposition is also frequently mentioned as an etiological factor for MEH $(13,14)$. The familial presence of the disease was first highlighted by Gómez et al in Columbia in 1969 (19). In 1993, Premoli-De-Percoco found that members of six generations of a Venezuelan family had been diagnosed with MEH and concluded that the disease has a genetic basis, noting that all generations were born in a small village with a very strong American Indian genetic component (37). In 2004, García-Corona et al assessed the effect of genetics by studying the association of HLA-DR4 alleles (DRB1*0404) with HPV infection, yielding results in support of the genetic basis of MEH (4).

Nutritional deficiencies and environmental factors have been proposed by certain authors (15), including poverty and the lack of hygiene (38). The role of immunosuppression is also under investigation. Feller et al reported the case of a seropositive child undergoing highly active antiretroviral treatment who was also diagnosed with MEH and successfully treated by diode laser; the authors suggested that the anti-HIV therapy may have been responsible for the disease (39). In another report on an HIV-positive patient with MEH, Marvan et al concluded that the correlation between the immune state and HPV infection warranted further investigation (40).

\section{Diagnosis, prognosis and treatment}

The diagnosis of MEH is mainly based on the clinical features of the lesions and a biopsy pathology report. Since the discovery of HPV particles in these lesions in 1970, there has been an increase in the diagnostic use of molecular biology techniques, including in situ DNA hybridization and polymerase chain reaction, which have proven highly useful in identifying the types of HPV involved $(2,5,27,28,31,41)$.

The prognosis of the disease is good, given that most lesions remit spontaneously, but periodical clinical follow-ups are considered crucial $(42,43)$. Lesions that do not remit or cause functional and/or aesthetic problems may be removed by various means (44-48), including surgery, cryotherapy, electrocoagulation, laser, chemical agents (e.g., retinoic acid) or immunostimulants (e.g., interferon).

\section{Criteria and variables included}

Inclusion criteria. The PubMed database was used to search the international literature up to April 2011, for the following key words: Focal epithelial hyperplasia, multifocal epithelial hyperplasia, Heck's disease, papillomavirus infections, HPV-13 and HPV-32. The search was not limited by publication year due to the scant information on the disease. Out of a total of 831 articles (in English, German and Spanish), 204 were initially selected for possible inclusion. After studying the abstracts, 68 relevant articles that could be downloaded via the Internet were selected, and a final sample of eight articles was included in the present review after applying the following inclusion criteria (Fig. 1): i) They could be any type

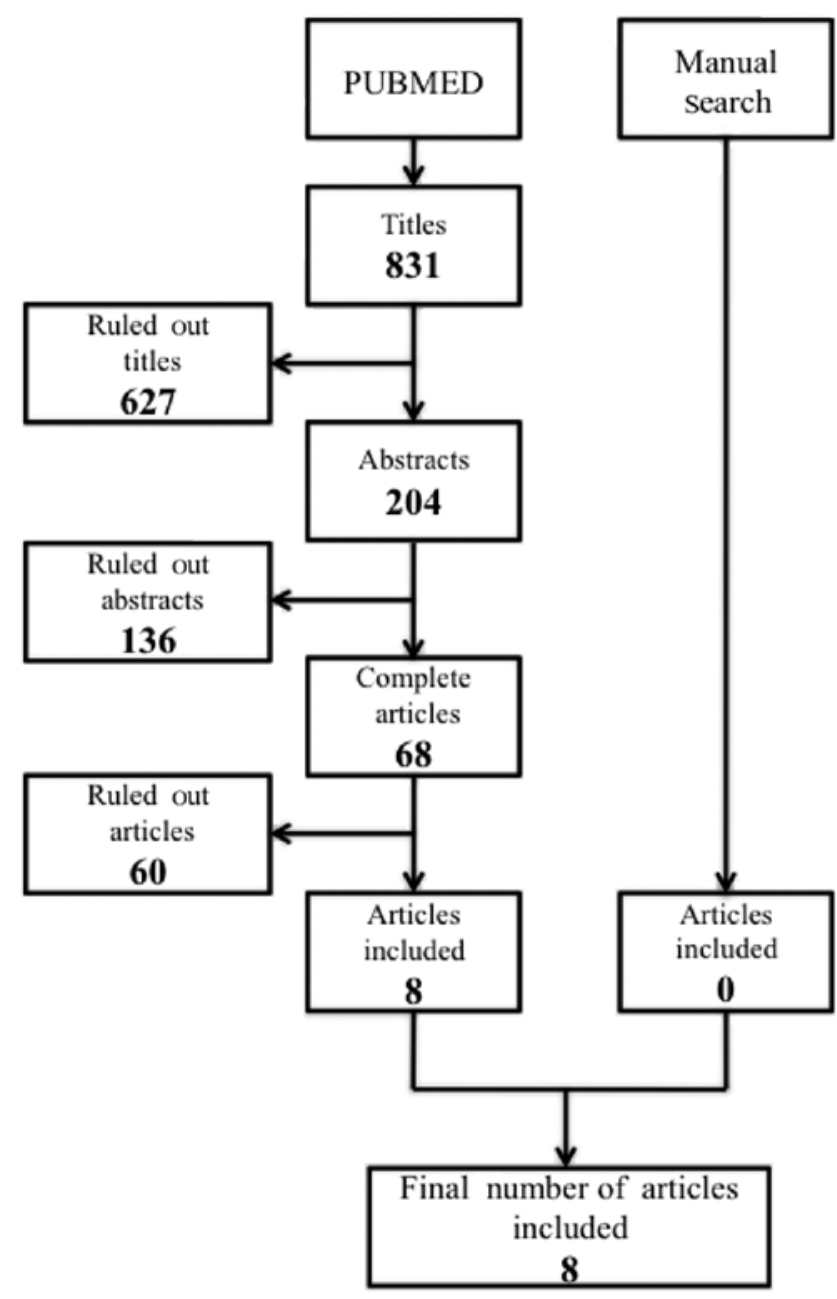

Figure 1. Flowchart for selection of articles on multifocal epithelial hyperplasia.

of publication with the exception of single case reports, ii) they had to be in vivo studies, iii) the objectives had to include the description of the clinical characteristics and etiology of MEH and/or the epidemiology of the disease, iv) they could report on any clinical situation, including the presence of another disease with the exception of cancer, v) the complete text of the articles had to be available, and vi) all publication dates up to April 2011 could be included.

Study variables. In an initial analysis, we gathered and analyzed the main variables related to the epidemiology of $\mathrm{EH}$, including the place of origin, geographic location, gender and age.

\section{Findings pertaining to multifocal epithelial hyperplasia}

There have been few studies on the epidemiology and incidence of MEH, attributable in part to its low incidence. The largest number of cases has been observed in Central America, South America and Mexico. The disease is less prevalent among individuals in Asia and is even more rare among Caucasian and Black populations.

In 1965, Witkop and Niswander (13) and Archard et al (14) conducted the first epidemiological studies on American Indians, finding a predisposition for the disease in individuals 
Table I. Distribution by decade of life.

\begin{tabular}{lcr}
\hline Age group & Number of cases & $\%$ \\
\hline First decade & 54 & 50.5 \\
Second decade & 50 & 47.0 \\
Third decade & 2 & 2.0 \\
Fourth decade & 1 & 0.5 \\
\hline
\end{tabular}

Table II. Distribution by localization.

\begin{tabular}{lcc}
\hline Localization & Number of cases & $\%$ \\
\hline Upper lip & 68 & 63.55 \\
Lower lip & 103 & 96.26 \\
Right buccal mucosa & 88 & 83.06 \\
Left buccal mucosa & 92 & 85.98 \\
Tongue & 73 & 68.22
\end{tabular}

Table III. Distribution by monthly income.

\begin{tabular}{lcr}
\hline Monthly income & Number of cases & $\%$ \\
\hline$\leq 100$ & 83 & 75.0 \\
$\$ 101$ to 184 & 10 & 15.0 \\
$\$ 185$ to 364 & 1 & 0.1 \\
$\$ 365$ to 910 & 0 & 0.0 \\
$>\$ 910$ & 1 & 0.1 \\
\hline
\end{tabular}

in the first and second decade of life, with the lower lip being the most frequent localization. However, whereas they found no significant gender difference, observing a larger number of males with the disease, Archard et al reported a female:male ratio of 4:1 $(13,14)$.

In a subsequent study on Eskimos in Greenland, Clausen et al found no significant gender differences. Furthermore, in contrast to previous studies, they found that the disease could also appear in adults, with an overall age range of 2 to 79 years, and that more than $50 \%$ of lesions were localized on the tongue (49). In a similar study, Henke et al found no significant gender or age differences and confirmed the possible presence of the disease in adults, reporting an age range for sufferers of 22 to 85 years $(50)$.

In 1994, Carlos and Sedano studied a sample of 110 patients diagnosed with MEH over a three-year period in the city and rural areas of Guatemala (36). They found that $69 \%$ of the patients were female (female:male ratio, 2.2:1).

In Table I, the age range of these patients was 5 to 38 years, the mean age was 11 years, and $97.5 \%$ were in their first or second decade of life. Although five cases were excluded due to lack of information on their age, it was concluded that this condition predominantly affects children and adolescents (36).

With regard to the localization of lesions (Table II), the majority were in non-keratinized mobile mucosa, excluding the soft palate, most frequently on the lower lip and buccal mucosa. Out of the 110 cases in this study, only three presented with single lesions (2.8\%): two on the lower lip and one on the tongue (36).

Tongue lesions were usually on the lateral borders, with only three cases of lesions on the ventral tongue and one on the dorsal tongue (36).

Socio-economic factors have been related to this disease. In Table III, cases are divided into five groups according to monthly family income. In nine of the 110 cases studied, the income group could not be established; $90 \%$ of the patients assessed were members of a family receiving less than $\$ 200$ a month. The only patient with a high monthly income (>\$910) was a 21-year-old female from a native village in Guatemala in which the presence of $\mathrm{MEH}$ has been reported. There were no cases among the 2,464 children in five private schools (36). These findings indicated a correlation between low socio-economic level and $\mathrm{MEH}$.

In 2004, García-Corona et al studied American Indians in 2004 and found no significant differences in gender, observing that $73 \%$ of cases were in the first and second decades of life, with a mean age of 19 years (4). A later study on Indians from Colombia by Gonzáles et al (3) found a predilection for the female gender $(63.3 \%)$ and a mean age of 9.8 years; the most common localization was the lower lip ( $66.7 \%$ of cases).

Finally, a study in Mexico by Ledesma-Montes et al (38) reported that $69.3 \%$ of patients were in their first or second decade of life and that the overall age range was 4 to 69 years; $71.1 \%$ were female. The most frequent localization was the buccal mucosa (82.6\%), followed by the lips and tongue $(67.3 \%)$.

None of the studies associated $\mathrm{MEH}$ with precancerous lesions, in spite of its close association with HPV, known to be an etiological factor in various malignant diseases.

\section{Conclusions}

MEH is a rare disease and its epidemiology has not been studied to a great extent. With regard to geographic localization, the majority of published cases are from the indigenous populations of the American continent and Eskimos from Greenland. The lips are the most frequent anatomical site of the disease. There is a higher prevalence in the first and second decades of life and a predilection for the female gender. Socio-economic and genetic factors, among others, have also been associated with the disease.

No correlation with malignant lesions has been reported, despite the relationship between MEH and HPV, which is an etiological agent in various precancerous lesions. However, only low-risk types of HPV have been related to the etiology of $\mathrm{MEH}$, and few cases have been reported.

There is a need for further studies in various populations to permit a wider systematic review and a more updated meta-analysis of this disease.

\section{References}

1. Saunders NR, Scolnik D, Rebbapragada A, et al: Focal epithelial hyperplasia caused by human papillomavirus 13 . Pediatr Infect Dis J 29: 550-552, 2010.

2. Cuberos V, Perez J, Lopez CJ, et al: Molecular and serological evidence of the epidemiological association of HPV 13 with focal epithelial hyperplasia: a case-control study. J Clin Virol 37: 21-26, 2006. 
3. Gonzalez LV, Gaviria AM, Sanclemente G, et al: Clinical, histopathological and virological findings in patients with focal epithelial hyperplasia from Colombia. Int J Dermatol 44: 274-279, 2005

4. Garcia-Corona C, Vega-Memije E, Mosqueda-Taylor A, et al: Association of HLA-DR4 (DRB1*0404) with human papillomavirus infection in patients with focal epithelial hyperplasia. Arch Dermatol 140: 1227-1231, 2004.

5. Premoli-de-Percoco G, Galindo I and Ramirez JL: In situ hybridization with digoxigenin-labelled DNA probes for the detection of human papillomavirus-induced focal epithelial hyperplasia among Venezuelans. Virchows Arch A Pathol Anat Histopathol 420: 295-300, 1992.

6. Hall C, McCullough M, Angel C and Manton D: Multifocal epithelial hyperplasia: a case report of a family of Somalian descent living in Australia. Oral Surg Oral Med Oral Pathol Oral Radiol Endod 109: 20-24, 2010.

7. Mosannen-Mozaffari P, Falaki F, Amirchaghmaghi M, Pakfetrat A, Dalirsani Z and Saghafi-Khadem S: Multifocal epithelial hyperplasia, a rare oral infection in Asia: report of twelve cases in Iran. Med Oral Patol Oral Cir Bucal 15: 591-595, 2009.

8. Falaki F, Amir Chaghmaghi M, Pakfetrat A, Delavarian Z, Mozaffari PM and Pazooki N: Detection of human papilloma virus DNA in seven cases of focal epithelial hyperplasia in Iran. J Oral Pathol Med 38: 773-776, 2009.

9. Ledesma-Montes C, Vega-Memije E, Garces-Ortiz M, Cardiel-Nieves M and Juarez-Luna C: Multifocal epithelial hyperplasia. Report of nine cases. Med Oral Patol Oral Cir Bucal 10: 394-401, 2005.

10. Van Wyk W and Harris A: Focal epithelial hyperplasia: a survey of two isolated communities in the Cape Province of South Africa. Community Dent Oral Epidemiol 15: 161-163, 1987.

11. Pilgard G: Focal epithelial hyperplasia. Report of nine cases from Sweden and review of the literature. Oral Surg Oral Med Oral Pathol 57: 540-543, 1984

12. Fischman SL: Focal epithelial hyperplasia. Case reports from Paraguay and Peru. Oral Surg Oral Med Oral Pathol 28: 389-393, 1969.

13. Witkop CJ Jr and Niswander JD: Focal epithelial hyperplasia in central and south american Indians and Ladinos. Oral Surg Oral Med Oral Pathol 20: 213-217, 1965.

14. Archard HO, Heck JW and Stanley HR: Focal epithelial hyperplasia: an unusual oral mucosal lesion found in Indian children. Oral Surg Oral Med Oral Pathol 20: 201-212, 1965.

15. Hettwer KJ and Rodgers MS: Focal epithelial hyperplasia (Heck's disease) in a Polynesian. Oral Surg Oral Med Oral Pathol 22 466-470, 1966

16. Phillips $\mathrm{H}$ and Williams A: Focal epithelial hyperplasia. Report of a case. Oral Surg Oral Med Oral Pathol 26: 619-622, 1968.

17. Waldman GH and Shelton DW: Focal epithelial hyperplasia (Heck's disease) in an adult Caucasian. Oral Surg Oral Med Oral Pathol 26: 124-127, 1968

18. Decker WG and De Guzman MN: Focal epithelial hyperplasia. Report of four cases in Mestizos from Cochabamba, Boliva. Oral Surg Oral Med Oral Pathol 27: 15-19, 1969.

19. Gomez A, Calle C, Arcila G and Pindborg JJ: Focal epithelial hyperplasia in a half-breed family of Colombians. J Am Dent Assoc 79: 663-667, 1969.

20. Tan KN, Medak H, Cohen L and Burlakow P: Focal epithelial hyperplasia in a Mexican Indian. Arch Dermatol 100: 474-477, 1969.

21. Hollander CF, and van Noord MJ: Focal epithelial hyperplasia: a virus-induced oral mucosal lesion in the chimpanzee. Oral Surg Oral Med Oral Pathol 33: 220-226, 1972.

22. Tate CL, Conti PA and Nero EP: Focal epithelial hyperplasia in the oral mucosa of a chimpanzee. J Am Vet Med Assoc 163 619-621, 1973.

23. Van Ranst M, Fuse A, Sobis H, et al: A papillomavirus related to HPV type 13 in oral focal epithelial hyperplasia in the pygmy chimpanzee. J Oral Pathol Med 20: 325-331, 1991

24. Sa LR, DiLoreto C, Leite MC, Wakamatsu A, Santos RT and Catao-Dias JL: Oral focal epithelial hyperplasia in a howler monkey (Alouatta fusca). Vet Pathol 37: 492-496, 2000.

25. Chen SY: Focal epithelial hyperplasia in rabbit oral mucosa. J Oral Pathol 8: 213-223, 1979

26. Syrjanen S: Human papillomavirus infections and oral tumors. Med Microbiol Immunol 192: 123-128, 2003

27. Praetorius-Clausen F and Willis JM: Papova virus-like particles in focal epithelial hyperplasia. Scand J Dent Res 79: 362-365, 1971.
28. Hanks CT, Fischman SL and Nino de Guzman M: Focal epithelial hyperplasia. A light and electron microscopic study of one case. Oral Surg Oral Med Oral Pathol 33: 934-943, 1972.

29. Kuffer R and Perol Y: Focal epithelial hyperplasia. 1st French case. Demonstration of a papovavirus by electron microscopy. Rev Stomatol Chir Maxillofac 77: 318-321, 1976.

30. Kuhlwein A, Nasemann T, Janner M, Schaeg G and Reinel D: Detection of papilloma virus in Heck's focal epithelial hyperplasia and the differential diagnosis of white-sponge nevus. Hautarzt 32: 617-621, 1981.

31. Pfister H, Hettich I, Runne U, Gissmann L and Chilf GN: Characterization of human papillomavirus type 13 from focal epithelial hyperplasia Heck lesions. J Virol 47: 363-366, 1983.

32. Beaudenon S, Praetorius F, Kremsdorf D, et al: A new type of human papillomavirus associated with oral focal epithelial hyperplasia. J Invest Dermatol 88: 130-135, 1987.

33. Syrjanen SM, Syrjanen KJ, Happonen RP and Lamberg MA: In situ DNA hybridization analysis of human papillomavirus (HPV) sequences in benign oral mucosal lesions. Arch Dermatol Res 279: 543-549, 1987.

34. Petzoldt D and Pfister H: HPV 1 DNA in lesions of focal epithelial hyperplasia Heck. Arch Dermatol Res 268: 313-314, 1980.

35. De Villiers EM, Neumann C, Le JY, Weidauer $H$ and zur Hausen $\mathrm{H}$ : Infection of the oral mucosa with defined types of human papillomaviruses. Med Microbiol Immunol 174: 287-294, 1986.

36. Carlos R and Sedano HO: Multifocal papilloma virus epithelial hyperplasia. Oral Surg Oral Med Oral Pathol 77: 631-635, 1994.

37. Premoli-De-Percoco G, Cisternas JP, Ramirez JL and Galindo I. Focal epithelial hyperplasia: human-papillomavirus-induced disease with a genetic predisposition in a Venezuelan family. Hum Genet 91: 386-388, 1993.

38. Ledesma-Montes C, Garces-Ortiz M and Hernandez-Guerrero JC: Clinicopathological and immunocytochemical study of multifocal epithelial hyperplasia. J Oral Maxillofac Surg 65: 2211-2217, 2007.

39. Feller L, Khammissa RA, Wood NH, Malema V, Meyerov R and Lemmer J: Focal epithelial hyperplasia (Heck disease) related to highly active antiretroviral therapy in an HIV-seropositive child. A report of a case, and a review of the literature. SADJ 65 $172-175,2010$.

40. Marvan E and Firth N: Focal epithelial hyperplasia in an HIV positive man. An illustrated case and review of the literature. Aust Dent J 43: 305-310, 1998 .

41. Bombeccari GP, Guzzi GP, Pallotti F and Spadari F: Focal epithelial hyperplasia: polymerase chain reaction amplification as a differential diagnosis tool. Am J Dermatopathol 31: 98-100, 2009.

42. Segura-Saint-Gerons R, Toro-Rojas M, Ceballos-Salobrena A, Aparicio-Soria JL and Fuentes-Vaamonde H: Focal epithelial hyperplasia. A rare disease in our area. Med Oral Patol Oral Cir Bucal 10: 128-131, 2005.

43. Hashemipour MA, Shoryabi A, Adhami S and Mehrabizadeh Honarmand H: Extensive focal epithelial hyperplasia. Arch Iran Med Jan 13: 48-52, 2009.

44. Martins WD, de Lima AA and Vieira S: Focal epithelial hyperplasia (Heck's disease): report of a case in a girl of Brazilian Indian descent. Int J Paediatr Dent 16: 65-68, 2006.

45. Dos Santos-Pinto L, Giro EM, Pansani CA, Ferrari J, Massucato EM and Spolidorio LC: An uncommon focal epithelial hyperplasia manifestation. J Dent Child (Chic) 76: 233-236, 2009.

46. Steinhoff M, Metze D, Stockfleth E and Luger TA: Successful topical treatment of focal epithelial hyperplasia (Heck's disease) with interferon-beta. Br J Dermatol 144: 1067-1069, 2001

47. Akyol A, Anadolu R, Anadolu Y, Ekmekci P, Gurgey E and Akay N: Multifocal papillomavirus epithelial hyperplasia: successful treatment with $\mathrm{CO}_{2}$ laser therapy combined with interferon alpha-2b. Int J Dermatol 42: 733-735, 2003.

48. Luomanen M: Oral focal epithelial hyperplasia removed with $\mathrm{CO}_{2}$ laser. Int J Oral Maxillofac Surg 19: 205-207, 1990.

49. Clausen FP, Mogeltoft M, Roed-Petersen B and Pindborg JJ: Focal epithelial hyperplasia of the oral mucosa in a south-west Greenlandic population. Scand J Dent Res 78: 287-294, 1970.

50. Henke RP, Milde-Langosch K, Loning T and Koppang HS: Human papillomavirus type 13 and focal epithelial hyperplasia of the oral mucosa: DNA hybridization on paraffin-embedded specimens. Virchows Arch A Pathol Anat Histopathol 411: 193-198, 1987. 